\title{
CONSEQUENCES OF WORKPLACE HARASSMENT/ VIOLENCE ON JOB OUTCOMES AMONG WOMEN EMPLOYEES IN THE HIGHER EDUCATION SECTOR OF PAKISTAN: MODERATION OF LEGAL ENVIRONMENT
}

\author{
Abida Khaliq ${ }^{1 \star}$, Dato' Sri ${ }^{2}$, Ashgar Ali Ali Mohamed ${ }^{3}$, Muhamad Hassan Ahmad ${ }^{4}$ \\ ${ }^{1}$ Ahmad Ibrahim Kulliyyah of Laws, International Islamic University Malaysia, \\ Abidakhaliq786@outlook.com \\ ${ }^{2}$ Prof., Civil Law Department, Ahmad Ibrahim Kulliyyah of Laws, International Islamic University \\ Malaysia \\ ${ }^{3}$ Dr., Civil Law Department, Ahmad Ibrahim Kulliyyah of Laws, International Islamic University \\ Malaysia \\ ${ }^{4}$ Asst. Prof. Dr., Civil Law Department, Ahmad Ibrahim Kulliyyah of Laws, International Islamic \\ University Malaysia \\ ${ }^{*}$ Corresponding Author
}

\begin{abstract}
Pervasiveness of incidents of violence is rising in the developing countries. Such violence at workplace has damaging consequences for the organizations and individual's health which need to be focused. Further, such violence can affect the individual's sound health and emotions. This study aims to investigate the influence of workplace violence (workplace injustice, workplace bullying and workplace aggression) on work outcomes (Job Satisfaction, organizational commitment, turnover intention and job burnout) through the moderating role of legal environment. This study is of cross-sectional and mix-method design. The selfadministered questionnaire was distributed to 474 faculty members belong to the different provinces of Pakistan through stratified sampling. The results reveal that workplace injustice has negative significant relationship with job satisfaction and organizational commitment. However, workplace injustice has insignificant relationship with turnover intention and job burnout. Furthermore, workplace aggression has negative significant relationship with job satisfaction and organizational commitment. Contrary to this, workplace aggression has positive significant relationship with turnover intention and job burnout. As well as workplace bullying is concerned, it has negative significant relationship with job satisfaction and organizational commitment. Though, workplace bullying has positive significant relationship with turnover intention and job burnout. Besides, legal environment does not moderate the relationship of workplace injustice with job satisfaction, turnover intention and job burnout. In addition, legal environment conditionally moderates the relationship of workplace injustice and organizational commitment. Correspondingly, legal environment significantly moderates the relationship of workplace bullying with job satisfaction, organizational commitment and turnover intention. However, legal environment conditionally moderates the relationship of workplace bullying and job burnout. Legal environment moderates the relationship of
\end{abstract}


workplace aggression and turnover intention. However, legal environment conditionally moderates the relationship of workplace aggression with job satisfaction, organizational commitment and job burnout. Thus, academic institutions should emphasize on the provision of legal environment, so that the incidents of violence can be diminished through proper implementations of actions.

Keywords: Workplace violence, Workplace injustice, workplace aggression, Workplace bullying, legal environment, job satisfaction, organizational commitment, turnover intention and burnout.

\section{INTRODUCTION}

Women at workplace face the issue of violence and don't proceed it due to fear and inappropriate results. Women belong to every field and anywhere in the world face such kind of harassment, but the developed nations have formulated the rules and implemented. Literature emphasizes that both academicians and practitioners have emphasized the importance of workplace violence for job outcomes [1]. Studies have also acknowledged the occurrence of stress, psychological and mental health disorders and deterioration in the quality of work due to workplace violence [2]. According to the study of Jafree [3], workplace violence undermines the performance of women at work while other studies also contributed that it leads to psychological disorders, physical illnesses, eating disorders and even emotional distress [4]. Workplace violence results in other negative consequences such as increase in absenteeism and intention to leave an organization as a result of workplace violence [5]. Previous studies have also mentioned that workplace violence is a major reason for health problems among employees such as stress disorders, heart problems etc. that again results in reduction of employee's productivity and even an increase in job burnout, turnover intention and early retirement [6]. In relation to this reports by the World Health Organization, 2015 indicate that approximately $30 \%-50 \%$ of workers report lethal exposure to physical violence. However, very few studies have contributed towards the theory of knowledge about workplace violence and its effects on job outcomes in developing countries like Pakistan. Furthermore, women from every filed of life face the issue of workplace violence. Likewise, teacher directed workplace violence is an unequivocal problem based on the prevalent problem in the education sector. The most common type of perpetrators of workplace violence against teachers are students,

According to Occupational Health Psychology 2012, that there are many dimensions of workplace violence such as verbal abuse, psychological distress and physical endangerment and these practices can even lead to the death of the employee [7]. Howard found that employees in the education sector consider physical assault to be more representative of workplace violence rather than other types of damages such as psychological, emotional and individual or institution's property damage [8]. Gregory, Cornell, and Fan conducted an interesting study in which they tried to find the victimization of teachers with authoritative school environment, discipline of students and support of students regarding study matters [9]. They found that schools with higher level of student support and structure has the lowest tendency of workplace violence [10]. Similarly, workplace violence also leads towards health problems and higher level of stress in individuals [11]. Despite of emerging focus on workplace violence, unfortunately little is known about the workplace violence and its consequences in developing countries like Pakistan.

However, suffering of the women from developing nation continues and its increasing with time. Such increasing trend of violence in the developing countries like Pakistan is due to the lack of studies focus on the workplace violence and role of legal environment towards the women related issues and job outcomes, government focus and implementation of the law at ground level. however, the study also signified that there is a growing need of attention required by researchers, practitioners, policy makers and even government to eliminate the hideous act of workplace violence [12]. Unfortunately, previous studies were either concerned with health sector or they were lacking in identifying the job outcome perspectives in relation to workplace violence. Many studies have contributed to the literature of job consequences and workplace violence such as the effect of workplace violence activities on sleep patterns [13], familial problems [14], fear [15], organizational citizenship behaviour [16], job engagement [17], job satisfaction [18], job burnout [19], organizational commitment [20], and turnover intention [21]. However, this condition is also observed in the survey of European Agency for Safety and Health at Work 2016, there is no comprehensive study that has seen the implications of workplace violence practices on job outcomes cumulatively while conferring to the education sector. The role of the legal environment in regulating this atrocious crime is also sporadic to the 
extent that there is hardly any study that has discoursed over such a critical factor. In addition to that, literature on Workplace Violence and Job Consequences is rare for developing countries especially in the context of Pakistan. This study will contribute in the understanding of workplace violence and its influence on the key work outcomes in the education sector through the buffer role of legal environment.

\subsection{Objectives of the Research}

1. To analyse the relationship between workplace violence and employee's key work outcomes.

2. To analyse the moderating role of legal environment between the relationship of workplace violence and employee's key work outcomes.

\subsection{Hypotheses}

$\mathbf{H}_{1}$ : Workplace Violence has negative significant relationship with job satisfaction.

$\mathbf{H}_{2}$ : Workplace Violence has negative significant relationship with organizational commitment.

$\mathbf{H}_{3}$ : Workplace Violence has positive significant relationship with turnover intention.

$\mathbf{H}_{4}$ : Workplace Violence has positive significant relationship with burnout.

$\mathbf{H}_{5}$ : Legal environment moderates the relationship between workplace violence and job satisfaction.

$\mathbf{H}_{6}$ : Legal environment moderates the relationship between workplace violence and organizational commitment.

$\mathbf{H}_{7}$ : Legal environment moderates the relationship between workplace violence and turnover intention.

$\mathbf{H}_{8}$ : Legal environment moderates the relationship between workplace violence and job burnout.

\subsection{LITERATURE REVIEW}

\subsubsection{Workplace Violence}

The European Commission has defined workplace violence as, "Incidents where persons assaulted in circumstances related to their work, involving an explicit or implicit violence". It affects employees from all ages and genders, but also has a direct impact on the organizations involved such as costs in increasing security, repairs, loss of productivity, negative publicity, lawyer's fees, importantly loss of employees/turnover [22]. Several studies show that each year millions of employees are affected by workplace violence which results in adverse outcomes such as higher turnover, burnout, lower productivity, lack of organizational commitment, lessened morale, fear etc. [23]

Verbal abuse (verbal attack or verbal assault) occurs when employee puts false accusation towards one's character [24] evaluates in a negative way or show anger [25]. Workplace violence can be categorized in many behaviors such as psychological abuse, threat to individual, verbal demoralization, physical assault and any other behavior that generate the sense of discomfort in individuals [26]. Unfortunately, workplace violence exists in almost all the workplaces such as transportation, health care, law enforcement sector and teaching as well. There are several types of workplace violence and are discussed in the following:

Many authors have defined workplace aggression in different terms such as Ferris, Yan, Lim, Chen, and Fatimah [27] has defined workplace aggression as the behaviour of retaliation by an individual or group towards someone or organization in response to any unfair situation or policy and especially when it is causing some type of harm, whether emotional or physical in nature, to the individual or group [28]. Another study has also described workplace aggression as a process in which an individual, whether intentionally or unintentionally, try to deliberately harm the other individual physically [29] or emotionally.

Needham termed workplace bullying as a massive destruction which is unavoidable to ignore [30]. In the literature, many studies have intensely exemplified the agony, mental distress, discomfort, physical illness, emotional harm, and career damage suffered by victims (targets) of bullying [31]. Workplace bullying occurs when an individual is subject to repeated negative social acts that places the target in an inferior position. Past research in the area of workplace bullying has shown far-reaching effects on the target of bullying, such as workplace withdrawal [32], physical health [33], and suicidal ideation [34], as well as bystanders [35].

Workplace injustice refers to the situation in which an individual or group of individuals perceive that the decisions of the organization which either directly or indirectly effects those individuals are not being taken on the fair basis [36]. Workplace injustice consists of three further types i.e. distributive injustice, procedural 
injustice and interactional injustice. Distributive injustice is the situation when the employee or the group of employees perceive that that there is inequality and unfairness in distribution of ones or a group of individual's outcomes. "Distributive justice refers to the how economic and social goods and services are fairly distributed in the society" [37]. The Fairness Theory explains that the co-workers analyse either the injustice was an incidental injustice, or it is because of the poor decision-making process adopted by the organization the latter is considered as the procedural injustice [38]. Procedural injustice has negative effects on the physical condition of a person, when the employee suffers from work stress, the strain can trigger a psychosomatic condition [39]. Interactional injustice can be explained by John R. Schermerhorn as the degree to which the people are affected by decision and are treated by dignity and respect [40]. The theory focuses on the interpersonal treatment people receive when procedures are implemented. Interactional justice is the situation where the employees perceive that they are being treated appropriately and believe that their respect and dignity level is being kept in mind by the organization during the interaction of the coworkers with them and they perceive that the required level of communication from appropriate level by the competent authority was being made at right time to explain the decision regarding those employee's [41].

\subsubsection{Workplace Violence and Employee's Work Outcomes:}

One of the major situational factors for workplace aggression is distributive injustice. Distributive injustice can be defined as the perception of individuals about the unfairness of outcomes [42], compared to the referent employees in organization. Individuals try to retaliate to such policies to restore justice [43]. Individuals adopt different methods to restore justice such as to reduce or waste inputs i.e. organization targeted aggression or to engage in counterproductive work behaviors, deviance etc.[44]. Organization can also adopt techniques to remove such perception of distributive injustice such as rebalancing the input-output ratio. However, a more common approach in literature is that whenever individuals feel that there is distributive injustice held against them, they find out the source from where such decision is being made and thus target such individuals in organization which mostly lead to other situational factor known as supervisor targeted aggression [45]. Similar is the case with procedural injustice. Perceived injustice means the unfairness in procedures while developing the outcomes or goals for individuals[46]. These stressors enhance the propensity of the employees to engage in aggression as such activities are one way to cope with the situation[47].

Mistreatment and ill-behavior affect the atmosphere of the organization resulting in higher rates of turnover [48]. Results from the study of Laschinger and Fida [49] highlighted the major eight effects of bullying on the targets are as mentioned, anxiety, downheartedness, fatigue, uncertainty, humiliation, bad dream, poor concentration, and restlessness. Business Research Lab [50] disclosed that every other person in the organization are being bullied at the workplace leading towards serious health issues which includes psychological disorders with higher ranks of depression [51]. Ambrose [52] stated that perception of employees or group of employees about the fairness of the decisions influences the successive behaviors and believes about the organization and this may result in influencing the performance of the employees.

According to researchers Sulu, Ceylan, and Kaynak,[52] justice predicts the multiple job outcomes i.e., turnover intentions, job stress, workplace sabotage, trust and organizational commitment. In contrast, Sulu et al.[53] have investigated a negative link in procedural and distributive injustice with organizational commitment. Moreover, it is also explored that distributive injustice increases the employee's turnover intention [54]. However, researchers have not explored a connection in organizational commitment and interactional justice. Conversely, Lambert, Hogan and Griffin [55] have investigated that procedural and distributive justices have significant influence on job stress and organizational commitment. Crow, Lee, and Joo [56] have also explored a significant and meaningful relationship with organizational commitment and organizational justice. They have also investigated that job satisfaction and distributive justice have partial mediating impact on the indirect link of commitment and organizational justice. While Elanain [57] has suggested in his study that management can bring improvement in job satisfaction and organizational commitment through improved distributive and procedural justice. Research shows that perceptions of injustice mediate the relationship between sexual harassment and organizational commitment, withdrawal intentions, and job performance abusive supervision and subsequent employee aggression; and working in a climate of workplace incivility and intention to remain with the organization [58]. To date, then, research and theory suggest that experiences of mistreatment are related to perceptions of injustice and, as a result, to declines in employees' well-being.

The rapid intensification in female teachers' turnover is putting the future generation's opportunities at risk. Female teacher turnover in the workplace is indicative of the fact that employees are prone to various from of workplace violence/harassment which includes physical and verbal abuse. Previous studies have conferred to the consequences or outcomes of job burnout among employees such as employee's turnover[59], 
productivity of individuals or organization, absenteeism and lack of sense of commitment by individual towards job or organization [60]. However, one thing that has been neglected over the years are the antecedents or factors that affect the job burnout in organizations. Previous studies have considered two types of factors namely individual and contextual factors [61] Individual's factors include employee's traits such as personality traits, emotionality etc. however contextual factors refer to factors that are imposed by organization or its management such as behaviors of leaders or supervisors, goals or stressful job activities. Another important contextual factor is coworker's behaviors, their personality traits, how emotionally sound they are etc. as coworkers always play an important role in employee's job life. Seemingly coworker's behaviors towards the other individuals, especially a discriminatory one, are one of the major factors that employees tend to leave the organizations. This can also be considered as workplace violence/harassment or its part thereof.

Such psychological breach of contract enhances the stressors and thus promotes negative actions from the aggrieved one as well such as deliberate lack of goal achievement, anger and decrease in organizational commitment [61]. These reactions can also be related to the turnover intention among employees. However, literature is dearth regarding the workplace violence/harassment and its effect on organizational commitment. Barling et al. [62] indicated that workplace violence/harassment significantly increases negative emotions among the health care employees which in turn reduced the organizational commitment of employees and enhanced the intention to leave the organization. Workplace violence/harassment was also associated with decreased productivity, deteriorated commitment and enhanced the turnover intention [60]. Workplace violence/harassment also produces the negative outcomes for employees regarding the job such as enhancement turnover intention, low job satisfaction [64], reduces the organizational commitment and emotional attachment to work and organization [61].

\subsection{RESEARCH METHODOLOGY}

In this study, positivism philosophy and deductive approach have utilized. To collect the data from the faculty of educational institutions of Pakistan, cross-sectional survey technique has utilized. For this purpose, stratified random sampling techniques have been considered as different strata were developed according to the provinces of Pakistan i.e. Punjab, Sindh, KPK and Baluchistan. A holistic sampling frame was developed by contacting Higher Education Commission and from the sampling frame according to the provinces. Based on random selection, different universities were selected for the data collection. The sample size of this study was calculated through Cohen's formula (1983) which was 110. However, 550 questionnaires were distributed through which 600 were collected and 474 were useable. The questionnaires of this study variables were adopted, and detail is given in the following table. This study utilizes the SPSS 21 to perform the descriptive analysis, regression and moderation analysis of Process technique. Ethical considerations are regarded as a vital part of the research process [63]. Being a researcher, it is my primary responsibility to be aware of the ethical implications for my participants [64]. This section discusses the key ethical issues relevant to the current study.

\section{Table 1}

\begin{tabular}{|c|c|c|}
\hline Variable & No. of Items & Author \\
\hline Job Satisfaction & 14 & Hackman and Oldham (1974)[65] \\
\hline Organizational Commitment & 23 & Meyer, Becker and Van Dick (2006) [66] \\
\hline Turnover Intention & 4 & Kelloway, Gottlieb, and Barham (1999) [67] \\
\hline Job Burnout & 22 & Maslach et al. (1986) [68] \\
\hline Workplace Injustice & 20 & Moorman (1991) [69] \\
\hline Workplace Bullying & 7 & Einarsen, Hoel, and Notelaers (2009)[70] \\
\hline Workplace Aggression & 15 & Einarsen, Hoel, and Notelaers (2009)[71] \\
\hline Legal Environment & 4 & $\begin{array}{c}\text { Government of Alberta (Employment and } \\
\text { Immigration), 2006[72] }\end{array}$ \\
\hline
\end{tabular}




\subsection{RESULTS}

This study describes the relationship among the current study variables while relating it with the education sector. This study also shed light on the role of the Legal environment, which is the proposed moderator of the study. In this study, the quantitative analysis was done through SPSS 21.

\subsubsection{Descriptive Analysis}

Table 1.1

\begin{tabular}{|c|c|c|}
\hline Respondent's Demographics & Frequency & Percentage \\
\hline \multicolumn{3}{|c|}{ Gender $(N=474)$} \\
\hline Male & 0 & 0 \\
\hline Female & 474 & 100.0 \\
\hline \multicolumn{3}{|c|}{ Age $(N=474)$} \\
\hline 21-30 Years & 312 & 65.8 \\
\hline $31-40$ & 133 & 28.1 \\
\hline $41-50$ & 27 & 5.7 \\
\hline $51 \&$ Above & 2 & .4 \\
\hline \multicolumn{3}{|c|}{ Marital Status $(\mathrm{N}=474)$} \\
\hline Married & 178 & 37.6 \\
\hline Single & 296 & 62.4 \\
\hline \multicolumn{3}{|c|}{ Experience $(\mathrm{N}=474)$} \\
\hline$<$ Year & 82 & 17.3 \\
\hline$>1-5$ Years & 262 & 55.3 \\
\hline$>5-10$ Years & 79 & 16.7 \\
\hline$>10-15$ Years & 37 & 7.8 \\
\hline$>15-20$ Years & 11 & 2.3 \\
\hline$>20-25$ Years & 2 & .4 \\
\hline$>25$ Years & 1 & .2 \\
\hline
\end{tabular}

It is shown in below table 1.1. that data is collected from the females only. The total number of female respondents were 474 . Table 1.1 also show the age of the respondents. There were $312(65.8 \%)$ respondents who fall in the range of 21 - 30 years of age, $133(28.1 \%)$ respondents were in the category of 31 - 40 years, 27 (5.7\%) respondents were in the age category of $41-50$ years and only 2 (0.4\%) respondents were in the age category of 51 \& above. Similarly, 37.6\% of the respondents were married whereas single were $62.4 \%$. further, 42 (8.9\%) respondents who belong to public sector and 432 (91.1\%) respondents were from private sector. Furthermore, $82(17.3 \%)$ of the total respondents were having the 
experience of less than a year, $262(55.3 \%)$ respondents were having the experience of 1-5 years, 79 $(16.7 \%)$ respondents were having the experience of $5-10$ years, $37(7.8 \%)$ respondents were having the experience of $10-15$ years, $11(2.3 \%)$ respondents were having the experience of $15-20$ years, $2(0.2 \%)$ respondents were experienced of $20-25$ years and only $1(0.2 \%)$ respondent was having the experience of more than 25 years.

\subsubsection{Sampling Adequacy Test}

The sampling adequacy is ensured KMO must be tested and its value should be greater than 0.5 or $0.6,[116$ 118]. further, KMO test assure the sampling was adequate or not[119]. Further Bartlett's test assures the suitability of the sample. Haier et al.[120] suggested multiple criteria to assess the sample, so this study fulfill the standard criteria of sampling adequacy and suitability.

Table 1.2

\begin{tabular}{|c|c|c|c|}
\hline Constructs & KMO & Approx. Chi Sq. & Bartlett's Test \\
\hline Job Satisfaction & .903 & 2423.891 & .000 \\
\hline $\begin{array}{c}\text { Organization } \\
\text { Commitment }\end{array}$ & .874 & 7096.819 & .000 \\
\hline Turnover Intention & .830 & 1027.502 & .000 \\
\hline Job Burnout & .838 & 4081.706 & .000 \\
\hline Workplace Injustice & .876 & 5147.384 & .000 \\
\hline Workplace Bullying & .868 & 1354.271 & .000 \\
\hline Workplace Aggression & .913 & 2119.912 & .000 \\
\hline
\end{tabular}

Table 1.2 shows the validity of this study variable. The results in table 1.2 mentions the validity of this study variables as it meets the standard criteria of validity (KMO>0.50, Bartlett's test of Sphericity; $P<0.05)$.

\subsubsection{Reliability \& Correlation Analysis}

Table 1.3

\begin{tabular}{|l|l|l|l|l|l|l|l|l|}
\hline & $\begin{array}{l}\text { Cronbach's } \\
\text { Alpha }\end{array}$ & JS & OC & TI & JB & WI & WB & WA \\
\hline JS & .883 & 1 & & & & & & \\
\hline OC & .907 & .083 & 1 & & & & & \\
\hline TI & .884 & $-.129^{* *}$ & $-.378^{* *}$ & 1 & & & & \\
\hline JB & .822 & $-.165^{* *}$ & -.068 & -.033 & 1 & & & \\
\hline WI & .886 & $-.110^{*}$ & $-.172^{* *}$ & .059 & .084 & 1 & & \\
\hline WB & .844 & $-.207^{* *}$ & $-.117^{*}$ & $.315^{* *}$ & $.226^{* *}$ & $.185^{* *}$ & 1 & \\
\hline WA & .961 & $-.299^{* *}$ & $-.171^{* *}$ & $.320^{* *}$ & $.263^{* *}$ & $.194^{* *}$ & $.719^{* *}$ & 1 \\
\hline
\end{tabular}

Table 1.3 shows the results of reliability of the variables. The results reveal that Cronbach's Alpha value of all the variables of this study meet the standard criteria $(\alpha>0.70)$ of reliability. So, the questionnaires of this study variables are reliable. Correlation value also mentions the strength of the relationship among the study 
variables.

\subsubsection{Regression Analysis}

Table 1.4

\begin{tabular}{|l|l|l|}
\hline & Sig. & Result \\
\hline WI $\rightarrow$ JS & .016 & Supported \\
\hline WB $\rightarrow$ JS & .000 & Supported \\
\hline WA $\rightarrow$ JS & .000 & Supported \\
\hline WI $\rightarrow$ OC & .000 & Supported \\
\hline WB $\rightarrow$ OC & .011 & Supported \\
\hline WA $\rightarrow$ OC & .000 & Supported \\
\hline WI $\rightarrow$ TI & .202 & Unsupported \\
\hline WB $\rightarrow$ TI & .000 & Supported \\
\hline WA $\rightarrow$ TI & .000 & Supported \\
\hline WI $\rightarrow$ BO & .068 & Unsupported \\
\hline WB $\rightarrow$ BO & .000 & Supported \\
\hline WA $\rightarrow$ BO & .000 & Supported \\
\hline
\end{tabular}

Table 1.4 shows the regression results of the workplace violence and work outcomes. The results reveal that workplace injustice, workplace bullying and workplace aggression has significant association with job satisfaction. Similarly, workplace injustice, workplace bullying and workplace aggression has significant relationship with organizational commitment. However, workplace injustice has insignificant relationship with turnover intention and burnout. Further, workplace bullying and workplace aggression has significant relationship with turnover intention burnout.

\subsubsection{Regression Analysis}

Table 1.5

\begin{tabular}{|l|l|l|}
\hline & \multicolumn{1}{|c|}{ Sig. } & \multicolumn{1}{c|}{ Result } \\
\hline $\mathrm{WI}^{\rightarrow} \mathrm{LE} \rightarrow \mathrm{JS}$ & 0.036 & Conditionally Moderate \\
\hline $\mathrm{W} \rightarrow \mathrm{LE} \rightarrow \mathrm{OC}$ & 0.021 & Conditionally Moderate \\
\hline $\mathrm{WI} \rightarrow \mathrm{LE} \rightarrow \mathrm{TI}$ & 0.447 & Unsupported \\
\hline $\mathrm{W} \rightarrow \mathrm{LE} \rightarrow \mathrm{BO}$ & 0.557 & Unsupported \\
\hline $\mathrm{WB} \rightarrow \mathrm{LE}$ JS & 0.003 & Supported \\
\hline $\mathrm{WB} \rightarrow \mathrm{LE}$ OC & 0.028 & Supported \\
\hline
\end{tabular}




\begin{tabular}{|c|c|c|}
\hline $\mathrm{WB} \overrightarrow{\mathrm{LE}} \overrightarrow{\mathrm{TI}}$ & 0.002 & Supported \\
\hline $\overrightarrow{\mathrm{WB}} \overrightarrow{\mathrm{LE}} \mathrm{BO}$ & 0.000 & Conditionally Moderate \\
\hline $\mathrm{WA} \rightarrow{ }_{\mathrm{LE}} \rightarrow \mathrm{JS}$ & 0.000 & Conditionally Moderate \\
\hline $\mathrm{WA}^{\rightarrow} \mathrm{LE} \rightarrow \mathrm{OC}$ & 0.000 & Conditionally Moderate \\
\hline $\mathrm{WA} \overrightarrow{\mathrm{LE}} \mathrm{TI}$ & 0.022 & Supported \\
\hline $\mathrm{WA} \rightarrow{ }_{\mathrm{LE}} \rightarrow \mathrm{BO}$ & 0.000 & Conditionally Moderate \\
\hline
\end{tabular}

Table 1.5 mentions the moderating role of legal environment between workplace violence (Workplace injustice, Aggression and Burnout) and work outcomes (Job satisfaction, organizational commitment, turnover intention and burnout). The results noted that legal environment moderates the relationship of workplace bullying with job satisfaction. Organizational commitment and turnover intention. Further, legal environment also moderated the relationship of workplace aggression and turnover intention. However, legal environment conditionally moderates the relationship of workplace injustice with job satisfaction and organizational commitment. Similarly, LE also conditionally moderates the relationship of workplace bullying with burnout, workplace aggression's relationship with job satisfaction, organization commitment and burnout. On the other hand, LE does not moderate the relationship of workplace injustice with turnover intention and burnout.

\subsection{DISCUSSION AND CONCLUSION}

Prevalence of violence is increasing for the academic professionals of developing countries which include injustice, bullying and aggression. Thus, academicians experience the issues of work outcomes and ultimately affect the organization's efficiency. Further, absence of the legal environment in the academic institutions of developing countries raises the issue of work outcomes and becomes the reason of employee's suffering. This study aims to investigate the influence of workplace violence (workplace injustice, workplace bullying and workplace aggression) on work outcomes (Job Satisfaction, organizational commitment, and turnover intention and job burnout) through the moderating role of legal environment.

The results show that workplace injustice has negative significant relationship with job satisfaction. Similarly, shows that workplace injustice has negative significant relationship with organizational commitment. These results are in line with the previous findings [73]. Further, workplace injustice has insignificant relationship with turnover intention and job burnout. The reason behind this insignificant relationship of violence with job behaviours is that the data was collected from the faculty of universities working in Lahore which may raise the issue of generalizability and injustice is also the norm in the private universities of developing countries. Further, job opportunities are also rare, so the individuals avoid the intention to leave the organization and negative behaviours. As well as the workplace bullying is concerned, workplace bullying has negative significant relationship with job satisfaction and organizational commitment. However, workplace bullying has positive significant relationship with turnover intention and job burnout [73]. Furthermore, workplace aggression has negative significant relationship with job satisfaction and organizational commitment. Contrary to this, workplace aggression has positive significant relationship with turnover intention and job burnout [74]. However, legal environment has key importance to shape the required attitude and behaviours of employees. The legal support from the organization in the presence of workplace violence plays an important role to attain the positive work outcomes. In this study, legal environment does not moderate the relationship of workplace injustice with job satisfaction, turnover intention and job burnout. However, legal environment conditionally moderates the relationship of workplace injustice and organizational commitment.

It is also established that workplace bullying has significant association with work outcomes. legal environment significantly moderates the relationship of workplace bullying with job satisfaction, organizational commitment and turnover intention. However legal environment conditionally moderates the relationship of workplace bullying and job burnout. On the other hand, legal environment moderates the relationship of workplace aggression and turnover intention. However, legal environment conditionally moderates the relationship of workplace aggression with job satisfaction, organizational commitment and job burnout. 
Thus, academic institutions should emphasize on the provision of the legal environment so that the incidents of violence can be diminished, and proper implementations of actions can be ensured. Teachers were asked to clarify their response regarding the effect on outcome of the jobs because of any workplace harassment or violence activity. Any respondent who faced such violence clearly mentioned that it affected their behaviors, performance and attitude etc. at some level. Victims faced fear, lack in self-confidence, mental instability, depression, self-doubt, dignity, turnover and job burnout. This also results in psychological pressure even issue gets resolved because that woman must face the same colleagues and environment that lead to such incivility. Respondent also indicated that if the victim is given proper laws and procedures, she may be able to cope up with the incident in a good manner.

\subsubsection{Limitation}

1- This study has collected the quantitative survey from only academicians, however, the violence issues in the other sectors like health care should be investigated as well.

2- In this study only three types of violence are considered, however, further studies should also emphasize on the other types of violence.

3- This study undertakes four work outcomes, so, the further studies should consider the employee's wellbeing as the key outcomes as well because violence may create serious issues of wellbeing.

4- In the current study legal environment is considered as the moderator, however, further studies should also consider the role of leadership support, national cultural aspects as the moderators.

\section{REFERENCE LIST}

1. Abed, M., E. Morris, and N. Sobers-Granum. "Workplace violence against medical staff in healthcare facilities in Barbados." Occupational medicine 66, no. 7 (2016): 580-583. ; Baron, Robert A., and Joel H. Neuman.

2. Kiewitz, Christian, Simon Lloyd D. Restubog, Mindy K. Shoss, Patrick Raymund James M. Garcia, and Robert L. Tang. "Suffering in silence: Investigating the role of fear in the relationship between abusive supervision and defensive silence." Journal of applied psychology 101, no. 5 (2016): 731.

3. Jafree, Sara Rizvi. "Workplace violence against women nurses working in two public sector hospitals of Lahore, Pakistan." Nursing outlook 65, no. 4 (2017): 420-427.

4. Wu, Long-Zeng, Frederick Hong-kit Yim, Ho Kwong Kwan, and Xiaomeng Zhang. "Coping with workplace ostracism: The roles of ingratiation and political skill in employee psychological distress. " Journal of Management Studies 49, no. 1 (2012): 178-199.

5. Cheung, Teris, and Paul SF Yip. "Workplace violence towards nurses in Hong Kong: prevalence and correlates." BMC public health 17, no. 1 (2017): 196; Hart, Rod, and Denise Heybrock. "Workplace Violence and Components of a Psychologically Healthy Workplace." Benefits quarterly 33, no. 1 (2017): 8-12.

6. Baba, Vishwanath V., Bella L. Galperin, and Terri R. Lituchy. "Occupational mental health: a study of work-related depression among nurses in the Caribbean." International journal of nursing studies 36, no. 2 (1999): 163-169.

7. Choi, Seung-Hye, and Haeyoung Lee. "Workplace violence against nurses in Korea and its impact on professional quality of life and turnover intention." Journal of nursing management 25, no. 7 (2017): 508-518.

8. Wassell, James T. "Workplace violence intervention effectiveness: A systematic literature review." Safety Science 47, no. 8 (2009): 1049-1055.

9. Brom, Sarah S., Gabriele Buruck, Irén Horváth, Peter Richter, and Michael P. Leiter. "Areas of worklife as predictors of occupational health-A validation study in two German samples." Burnout Research 2, no. 2-3 (2015): 60-70

10.Heponiemi, Tarja, Anne Kouvonen, Marianna Virtanen, Jukka Vänskä, and Marko Elovainio. "The prospective effects of $\mathrm{w}$ orkplace violence on physicians' job satisfaction and turnover intentions: the 
buffering effect of job control." BMC health services research 14, no. 1 (2014): 19.

11.Brower, Kirk J. "Organization-Level Interventions to Promote Physician Health and Well-Being: From Taking Care of Physicians to Giving Care to Patients." In Physician Mental Health and Well-Being, pp. 295-323. Springer, Cham, 2017.

12. Howard, Jack L., and Barbara A. Wech. "A model of organizational and job environment influences on workplace violence." Employee Responsibilities and Rights Journal 24, no. 2 (2012): 111-127.

13.Gregory, Anne, Dewey Cornell, and Xitao Fan. "Teacher safety and authoritative school climate in high schools." American Journal of Education 118, no. 4 (2012): 401-425.

14. Okechukwu, Cassandra A., Kerry Souza, Kelly D. Davis, and A. Butch de Castro. 'Discrimination, harassment, abuse, and bullying in the workplace: contribution of workplace injustice to occupational health disparities." American journal of industrial medicine 57, no. 5 (2014): 573-586.

15.Yıldırım, D. "Bullying among nurses and its effects." International nursing review 56, no. 4 (2009): 504511.

16. Espelage, Dorothy L., Sabina Low, Joshua R. Polanin, and Eric C. Brown. "The impact of a middle school program to reduce aggression, victimization, and sexual violence." Journal of Adolescent Health 53, no. 2 (2013): 180-186.

17.Gluschkoff, Kia, Marko Elovainio, Taina Hintsa, Jaana Pentti, Paula Salo, Mika Kivimäki, and Jussi Vahtera. "Organisational justice protects against the negative effect of workplace violence on teachers' sleep: A longitudinal cohort study." Occup Environ Med 74, no. 7 (2017): 511-516.

18.Najafi, Fereshteh, Masoud Fallahi-Khoshknab, Fazlollah Ahmadi, Asghar Dalvandi, and Mehdi Rahgozar."Human dignity and professional reputation under threat: Iranian Nurses' experiences of workplace violence." Nursing \& health sciences 19, no. 1 (2017): 44-50.

19.Ahmed, Saba, and Sajid Bashir. "Power of Negative Emotions at workplace: Envy, Subjective career success, Thriving at work with moderating role of Self-control."

20.Lee, Kibeom, and Natalie J. Allen. "Organizational citizenship behavior and workplace deviance: The role of affect and cognitions." Journal of applied psychology 87, no. 1 (2002): 131.

21.Ford, Dianne P., Susan E. Myrden, and E. Kevin Kelloway. "Workplace aggression targets' vulnerability factor: Job engagement." International journal of workplace health management 9, no. 2 (2016): 202220.

22.Galletta, Maura, Igor Portoghese, Maria Pietronilla Penna, Adalgisa Battistelli, and Luisa Saiani. "Turnover intention among Italian nurses: The moderating roles of supervisor support and organizational support." Nursing \& health sciences 13, no. 2 (2011): 184-191.

23.Courcy, François, Alexandre JS Morin, and Isabelle Madore. "The effects of exposure to psychological violence in the workplace on commitment and turnover intentions: The moderating role of social support and role stressors." Journal of interpersonal violence (2016): 0886260516674201.

24. Heponiemi, Tarja, Anne Kouvonen, Marianna Virtanen, Jukka Vänskä, and Marko Elovainio. "The prospective effects of workplace violence on physicians' job satisfaction and turnover intentions: the buffering effect of job control." BMC health services research 14, no. 1 (2014): 19.

25.Barak, Michalle E. Mor. "Managing diversity": Toward a globally inclusive workplace. Sage Publications, 2016.

26.Schat, Aaron $\mathrm{CH}$, Michael R. Frone, and E. Kevin Kelloway. "Prevalence of Workplace Aggression in the US Workforce": Findings From a National Study.(2006).;

27.Spence Laschinger, Heather K., Michael Leiter, Arla Day, and Debra Gilin. "Workplace empowerment, incivility, and burnout: Impact on staff nurse recruitment and retention outcomes." Journal of nursing management 17, no. 3 (2009): 302-311.

28.Bedi, Akanksha, and Aaron $\mathrm{CH}$ Schat. "Employee revenge against uncivil customers." Journal of Services Marketing 31, no. 6 (2017): 636-649.

29.Ferris, D. Lance, Ming Yan, Vivien KG Lim, Yuanyi Chen, and Shereen Fatimah. "An approachavoidance framework of workplace aggression." Academy of Management Journal 59, no. 5 (2016): 
1777-1800.

30.Needham, Andrea W. Workplace bullying: A costly business secret. Auckland, New Zealand: Penguin books, 2003.

31.Vickers, Margaret H. "Bullying, disability and work: A case study of workplace bullying." Qualitative Research in Organizations and Management: An International Journal 4, no. 3 (2009): 255-272.

32.Laschinger, Heather Spence, and Roberta Fida. "Longitudinal analysis authentic leadership on workplace bullying, burnout and turnover intentions." In Academy of Management Proceedings, vol. 2013, no. 1, p. 10065. Briarcliff Manor, NY 10510: Academy of Management, 2013.

33.Nielsen, Morten Birkeland, Tone Tangen, Thormod Idsoe, Stig Berge Matthiesen, and Nils Magerøy. "Post-traumatic stress disorder as a consequence of bullying at work and at school. A literature review and meta-analysis." Aggression and violent behavior 21 (2015): 17-24.

34.Nielsen, Morten Birkeland, Geir Høstmark Nielsen, Guy Notelaers, and Ståle Einarsen. "Workplace bullying and suicidal ideation: A 3-wave longitudinal Norwegian study." American Journal of Public Health 105, no. 11 (2015): e23-e28.

35.Samnani, Al-Karim, and Parbudyal Singh. "20 years of workplace bullying research: a review of the antecedents and consequences of bullying in the workplace." Aggression and Violent Behavior 17, no. 6 (2012): 581-589.

36.Lambert, Eric G., and Nancy L. Hogan. "Association between distributive and procedural justice and life satisfaction among correctional staff: Research note." Professional Issues in Criminal Justice 6, no. 3/4 (2011): 31-41.

37.Folger, Robert, and Russell Cropanzano. "Fairness theory: Justice as accountability." Advances in organizational justice 1 (2001): 1-55.

38.Dörfel, Martin, and Manfred Schmitt. "Procedural injustice in the workplace, sensitivity to befallen injustice, and job satisfaction." (1997).

39.Schermerhorn, John R., and Michel H. Bond. "Upward and downward influence tactics in managerial networks: A comparative study of Hong Kong Chinese and Americans." Asia Pacific Journal of Management 8, no. 2 (1991): 147-158.

40.Bies, Robert J., and Joseph S. Moag. "Interactional communication criteria of fairness." Research in organizational behavior 9 (1986): 289-319.

41.Nielsen, Morten Birkeland, Tone Tangen, Thormod Idsoe, Stig Berge Matthiesen, and Nils Magerøy. "Post-traumatic stress disorder as a consequence of bullying at work and at school. A literature review and meta-analysis." Aggression and violent behavior 21 (2015): 17-24.

42.Nielsen, Morten Birkeland, Geir Høstmark Nielsen, Guy Notelaers, and Ståle Einarsen. "Workplace bullying and suicidal ideation: A 3-wave longitudinal Norwegian study." American Journal of Public Health 105, no. 11 (2015): e23-e28.

43.Samnani, Al-Karim, and Parbudyal Singh. "20 years of workplace bullying research: a review of the antecedents and consequences of bullying in the workplace." Aggression and Violent Behavior 17, no. 6 (2012): 581-589.

44.Skarlicki, Daniel P., and Robert Folger. "Retaliation in the workplace: The roles of distributive, procedural, and interactional justice." Journal of applied Psychology 82, no. 3 (1997): 434.

45.Farrell, Gerry, and Katrina Cubit. "Nurses under threat: a comparison of content of 28 aggression management programs." International journal of mental health nursing 14, no. 1 (2005): 44-53.

46.Collins, Brian J., and Kevin W. Mossholder. "Fairness means more to some than others: Interactional fairness, job embeddedness, and discretionary work behaviors." Journal of Management 43, no. 2 (2017): 293-318.

47.Cowie, Helen, Paul Naylor, lan Rivers, Peter K. Smith, and Beatriz Pereira. "Measuring workplace bullying." Aggression and violent behavior 7, no. 1 (2002): 33-51.

48.Laschinger, Heather Spence, and Roberta Fida. "Longitudinal analysis authentic leadership on workplace bullying, burnout and turnover intentions." In Academy of Management Proceedings, vol. 2013, no. 1, 
p. 10065. Briarcliff Manor, NY 10510: Academy of Management, 2013.

49.Ambrose, Maureen L., Mark A. Seabright, and Marshall Schminke. "Sabotage in the workplace: The role of organizational injustice." Organizational behavior and human decision processes 89, no. 1 (2002): 947-965.

50.Muqadas, Farwa, Ch Abdul Rehman, and Usman Aslam. "Organizational justice and employee's job dissatisfaction: a moderating role of psychological empowerment." Pakistan Business Review 18, no. 4 (2017): 848-864.

51.Muqadas, Farwa, Muhammad llyas, and Usman Aslam. "ANTECEDENTS OF KNOWLEDGE SHARING AND ITS IMPACT ON EMPLOYEES'CREATIVITY AND WORK PERFORMANCE." Pakistan business review 18, no. 3 (2016): 655-674.

52.Gabriel, Allison S., Marcus M. Butts, Zhenyu Yuan, Rebecca L. Rosen, and Michael T. Sliter. "Further understanding incivility in the workplace: The effects of gender, agency, and communion." (2017).

53.Bell, Sue Ellen, and James R. Hulbert. "Translating social justice into clinical nurse specialist practice." Clinical Nurse Specialist 22, no. 6 (2008): 293-299.

54.Rowan, John. The reality game: A guide to humanistic counselling and psychotherapy. Routledge, 2016.

55.Peralta, Louisa R., Donna O'Connor, Wayne G. Cotton, and Andrew Bennie. "Pre-service physical education teachers' indigenous knowledge, cultural competency and pedagogy: A service learning intervention." Teaching Education 27, no. 3 (2016): 248-266.

56.Laeeque, Syed Harris, Atif Bilal, Samreen Babar, Zoya Khan, and Saif UI Rahman. "How patientperpetrated workplace violence leads to turnover intention among nurses: The mediating mechanism of occupational stress and burnout." Journal of Aggression, Maltreatment \& Trauma 27, no. 1 (2018): 96-118.

57.Sokka, Laura, Marianne Leinikka, Jussi Korpela, Andreas Henelius, Lauri Ahonen, Claude Alain, Kimmo Alho, and Minna Huotilainen. "Job burnout is associated with dysfunctions in brain mechanisms of voluntary and involuntary attention." Biological Psychology 117 (2016): 56-66.

58.De Hoogh, Annebel HB, and Deanne N. Den Hartog. "Ethical and despotic leadership, relationships with leader's social responsibility, top management team effectiveness and subordinates' optimism: A multi-method study." The Leadership Quarterly 19, no. 3 (2008): 297-311.

59. https://www.google.com/url?sa=t\&rct=i\&q=\&esrc=s\&source=web\&cd=12\&ved=2ahUKEwirwJvMwafkAhX Qh1wKHd4yDCoQFjALegQIAhAC\&url=https\%3A\%2F\%2Fopen.alberta.ca\%2Fdataset\%2Fe7d32d971316-4c06-98f9-72f80655a0c3\%2Fresource\%2Fd486e8ad-aa03-45f4-bdd9

6b5fba340fdb\%2Fdownload\%2Fzz-2006-11-preventing-violence-and-harassment-at-theworkplace.pdf\&usg=AOvVaw275Le_93VIdF6hUTrPTOlc

60.Hair, J. F., Black, W. C., \& Babin, B. J. (2010). RE Anderson Multivariate data analysis: A global perspective. New Jersey, Pearson Prentice Hall,).

61.Pallant, J. F. (2000). Development and validation of a scale to measure perceived control of internal states. Journal of Personality Assessment, 75(2), 308-337.

62.Tabachnick, B. G. \& Fidell, L. S. (2007). Using Multivariate Statistics. 5th edition. Boston, MA:Pearson Education. Inc.

63.Maat, S. M., Zakaria, E., Nordin, N. M., \& Meerah, T. S. M. (2011). Confirmatory factor analysis of the mathematics teachers' teaching practices instrument. World Applied Sciences Journal, 12(11), 2092 2096.

64.Kiewitz, 1; Michel, Jesse S., and Michael B. Hargis. "What motivates deviant behavior in the workplace? An examination of the mechanisms by which procedural injustice affects deviance." Motivation and Emotion 41, no. 1 (2017): 51-68; Najafi, 1; Roche, Michael, Donna Diers, Christine Duffield, and Christine Catling-Paull. "Violence toward nurses, the work environment, and patient outcomes." Journal of Nursing Scholarship 42, no. 1 (2010): 13-22.

65.Ayoko, Oluremi B., Victor J. Callan, and Charmine EJ Härtel. "Workplace conflict, bullying, and counterproductive behaviors." The International Journal of Organizational Analysis 11, no. 4 (2003): 283-301 
66. Brees, Jeremy, Mark Martinko, and Paul Harvey. "Abusive supervision: subordinate personality or supervisor behavior?." Journal of Managerial Psychology 31, no. 2 (2016): 405-419

67. Chen, Shiying, Shaowei Lin, Qishuang Ruan, Huangyuan Li, and Siying Wu. "Workplace violence and its effect on burnout and turnover attempt among Chinese medical staff." Archives of environmental \& occupational health 71, no. 6 (2016): 330-337

68. Espelage, Dorothy L., Sabina Low, Joshua R. Polanin, and Eric C. Brown. "The impact of a middle school program to reduce aggression, victimization, and sexual violence." Journal of Adolescent Health 53, no. 2 (2013): 180-186

69. Heckemann, B., A. Zeller, Sabine Hahn, T. Dassen, J. M. G. A. Schols, and R. J. G. Halfens. "The effect of aggression management training programmes for nursing staff and students working in an acute hospital setting. A narrative review of current literature." Nurse education today 35, no. 1 (2015): 212219

70.Kiewitz, Christian, Simon Lloyd D. Restubog, Mindy K. Shoss, Patrick Raymund James M. Garcia, and Robert L. Tang. "Suffering in silence: Investigating the role of fear in the relationship between abusive supervision and defensive silence." Journal of applied psychology 101, no. 5 (2016): 731.

71.Ambrose, Maureen L., Mark A. Seabright, and Marshall Schminke. "Sabotage in the workplace: The role of organizational injustice." Organizational behavior and human decision processes 89, no. 1 (2002): 947-965

72.Hsu, Hsiu-Yueh, Sheng-Hwang Chen, Hsing-Yi Yu, and Jiunn-Horng Lou. "Job stress, achievement motivation and occupational burnout among male nurses." Journal of advanced nursing 66, no. 7 (2010): 1592-1601

73. Ford, Dianne P., Susan E. Myrden, and E. Kevin Kelloway. "Workplace aggression targets' vulnerability factor: Job engagement." International journal of workplace health management 9, no. 2 (2016): 202220

74. Heckemann, B., A. Zeller, Sabine Hahn, T. Dassen, J. M. G. A. Schols, and R. J. G. Halfens. "The effect of aggression management training programmes for nursing staff and students working in an acute hospital setting. A narrative review of current literature." Nurse education today 35, no. 1 (2015): 212219. 